\title{
Vibration Characteristics of Composite Footbridges under Various Human Running Loads
}

\author{
Faraz Sadeghi, ${ }^{1,2}$ Ahmad Kueh,, ${ }^{1,2}$ Ali Bagheri Fard, ${ }^{2}$ and Nasim Aghili ${ }^{3}$ \\ ${ }^{1}$ UTM Construction Research Centre (UTM-CRC), Universiti Teknologi Malaysia (UTM), 81310 Johor Bahru, Malaysia \\ ${ }^{2}$ Civil Engineering Faculty, Universiti Teknologi Malaysia (UTM), 81310 Johor Bahru, Malaysia \\ ${ }^{3}$ Faculty of Geoinformation and Real Estate, Universiti Teknologi Malaysia (UTM), 81310 Johor Bahru, Malaysia
}

Correspondence should be addressed to Faraz Sadeghi; faraz.sadeghi86@yahoo.com

Received 6 August 2013; Accepted 3 September 2013

Academic Editors: R. S. Jangid and B. Uy

Copyright (C) 2013 Faraz Sadeghi et al. This is an open access article distributed under the Creative Commons Attribution License, which permits unrestricted use, distribution, and reproduction in any medium, provided the original work is properly cited.

\begin{abstract}
Various types of human running dynamic loads are numerically studied and compared to assess vibration characteristics of the light and slender composite footbridges. Running, which is a common human activity, has been categorized with respect to its intensity into jogging, normal running, and sprinting. To explore the footbridge's performance, the vibration responses are investigated through a series of analyses in terms of the peak accelerations and displacements. In the model verification, the acquired first natural frequency of structure has shown good agreement with the value reported in the literature. The structural performance of the slender composite footbridge is then evaluated with regard to the serviceability requirement given by the current design standards. It is generally found that the maximum acceleration of the composite footbridge due to the excitation of one person running varies under different running types because of diversities in the velocity and the step frequency. Furthermore, it is shown that the investigated structure provides sufficient human comfort against vibrations for all the examined three types of running loads.
\end{abstract}

\section{Introduction}

Lightweight and slender footbridges as advanced structures have been highly constructed for various engineering purposes in the recent years. Although from the structural point of view, footbridges have been properly designed according to existing construction and design codes, over the past few years, better accuracy analyses are needed for sophisticated structures [1]. It has been scientifically shown that in slender and light structures, such as footbridges, there is a coincidence between the domains of the natural frequencies and the frequencies of dynamic loads coming from the human induced activities such as walking, dancing, running, and jumping $[2,3]$. Such phenomenon has commonly associated with the existence of resonance which as a result causes disastrous damage to the structure.

Since the procedure of footbridges analysis due to the human induced loads like people running is weakly captured by point of experimental evidence [1], because of various undetermined interlinked effects, in this study we are aiming to generate a fundamental research knowledge on the vibration characteristics of the slender composite footbridge structures subject to different types of human running such as jogging, standard running, and sprinting to assess the serviceability requirements of such structures against the current design codes.

Footbridges vibration responses are considered through the analyses of natural frequency, acceleration, and displacement values. The natural frequency is a significant parameter in the vibration serviceability design. It represents the frequency of a free vibration of a structure that is displaced and quickly released [4]. The most important natural frequency of a structure is its first or the lowest frequency known as the fundamental natural frequency. It is commonly used as design parameter in preventing the matching of the load excitation frequency to avoid the resonance [4]. The fundamental natural frequency can be expressed [4] as

$$
f_{s}=0.18 \sqrt{\frac{g}{\Delta}},
$$

where $f_{s}, g$, and $\Delta$ are the fundamental frequency, acceleration of gravity $\left(9.81 \mathrm{~m} / \mathrm{s}^{2}\right)$, and deflection at the midspan of 
member, respectively. This simplified method can be used in a preliminary evaluation of natural frequencies. However, to model pedestrian excitation, a more precise method should be used. In this study, a modal analysis is utilized with the finite element tool to determine natural frequency, which is widely spread in all stages of the modern design. In addition, eigenvector analysis which is used to determine the natural frequency can be presented as

$$
\left(K-\Omega^{2} M\right) \varphi=0,
$$

where $K, M, \Omega^{2}$, and $\varphi$ are the stiffness matrix, the diagonal mass matrix, the diagonal matrix of eigenvalues and the matrix of corresponding eigenvectors (mode shapes), respectively.

\section{Human Running as Vibration Source}

Applying human discomfort criteria as the appraisal of the vibration of the floor structures has been the recent practice in the process of design [2]. It is a procedure that is subjected to the problem that involves various aspects. The induced loads by human activities and the dynamic response that is based on various modes of the vibration are complex. The vast majority of studies pointed out that the problem can be simplified adequately to conform to the design criteria $[4,5]$. The human activities induced dynamic excitation can be represented as a combination of the harmonic forces. In any case, it is assumed that the induced forces by human feet are similar to the model of the walking and running in time domain $[6,7]$. Equation (3) describes these harmonic forces by means of the Fourier series:

$$
F(t)=P\left(1+\sum_{i=1}^{n} \alpha_{i} \cos \left(2 \pi i f_{s} t+\varphi_{i}\right)\right),
$$

where $P$ is the weight of one person and $\alpha_{i}$ is the dynamic coefficient of the harmonic force, which is based on experimental tests. $i, f_{s}, t$, and $\varphi$ are the harmonic multiple, the step frequency, time, and harmonic phase angle, respectively. Figure 1 presents the dynamic load factors (DLFs), $\alpha_{i}$, of the first four harmonics corresponding to the frequency induced by various types of the running.

In the vibration of the floors, the first natural frequency is typically excited by the human activities since higher vibration modes are more difficult to excite. The reason is that the panels should shift in the opposite directions to respond to higher mode of vibration [4]. Due to generation of a concentrated load in the certain locations of the structure that is resulted from the human induced load in the case of the walking or the running, there exists a possibility of the coincidence between the first natural frequency of structure and the excitation frequencies of such dynamic loads which leads to resonance characterized by higher modes of vibration [6-8]. In this investigation, we have considered the lowest mode of vibration for human jogging, running, and sprinting based on the prevalent design method since the higher modes are excited just by components of small harmonic force [4].

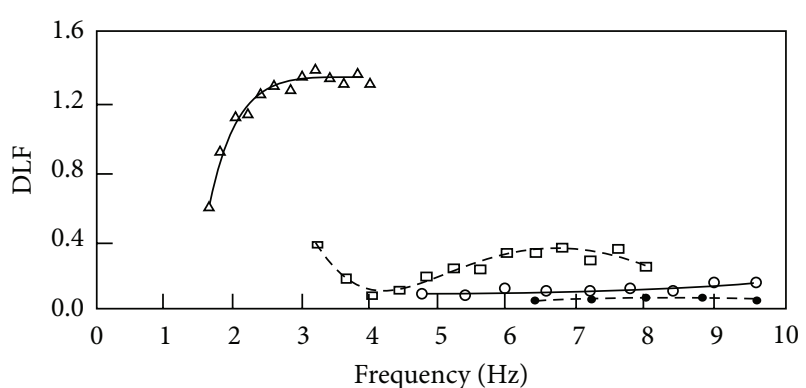

Harmonic

$\begin{array}{ll}\Delta 1 & \circ 3 \\ \square 2 & \bullet 4\end{array}$

Figure 1: The dynamic load factors (DLFs) of the first four harmonics corresponding to frequency induced by various types of the pedestrian running [2].

Dynamic excitations induced by different types of human running create small values of forces in the structural system, which are effective in the process of the controlling of the maximum acceleration and the resonance. The way that this process works is by increasing the structural mass or damping.

Even though increasing the mass or damping of the structure could be a solution of controlling human motion induced loads, excessive maximum acceleration occurs due to large dynamic forces coming from jumping, gymnastics, or dancing. Therefore, it constitutes a complicated synchronization of excessive maximum acceleration at resonance. Since the aim of vibration analysis is to provide human comfort through adjustment of the excessive vibration, the first natural frequency of the structure is obligated to be larger than the dynamic excitation frequency of the highest harmonic. Besides, the resonance is considered when the vibration frequency is in the range of $4 \mathrm{~Hz}$ and $8 \mathrm{~Hz}$ [4].

\section{Acceptance Criteria}

In the case of floor system, for the purpose of achieving vibration serviceability limit state resulting from any type of human running, the vibration response criterion will be referred to the design standard [4] for indoor footbridges, outdoor footbridges, and residences through the use of the following criteria: the acceleration limit values and the harmonic force component.

3.1. Peak Acceleration Limit Values. International Standard Organization (ISO) 2631-2 [9] guideline has recommended the acceleration limit values. These values are proposed as a multiple of the baseline curve of root mean square acceleration which are demonstrated in Figure 2. It is apparent that these design criteria are 100 for outdoor footbridges, which are related to frequency, and duration of vibration can be considered as $0.8-1.5$ times the recommended value [9] for design proposes. 


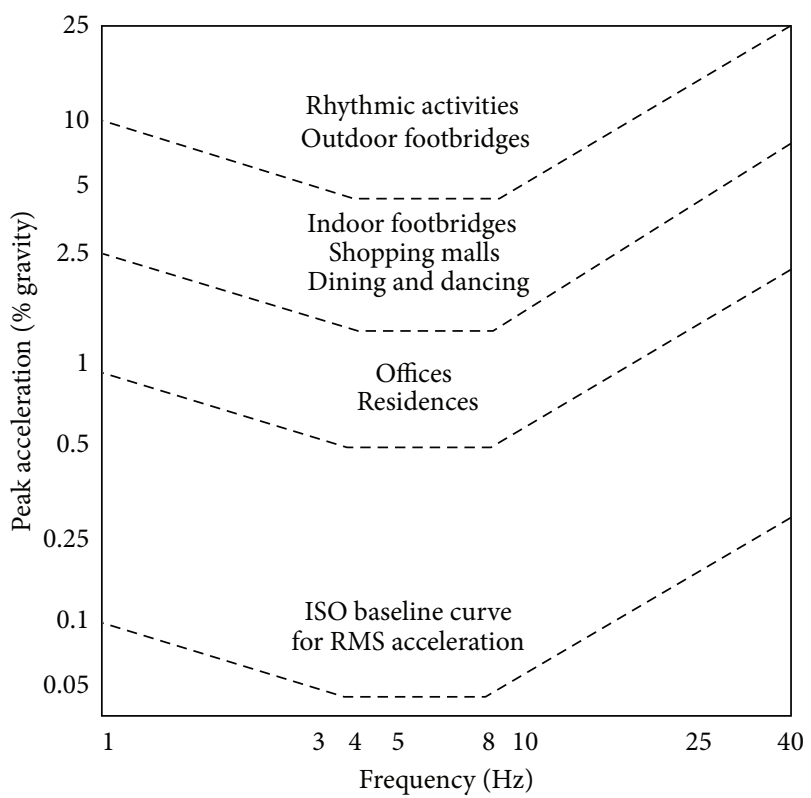

FIGURE 2: Human comfort criteria based on peak acceleration due to human activities from ISO 2631-2 [9].

3.2. The Harmonic Force Component. A time-dependent harmonic force component which occurs at the same time with the structural fundamental frequency can be written as

$$
F(t)=P \alpha_{i} \cos \left(2 \pi i f_{s} t\right) .
$$

In our case (running), the static load $(P)$ is $700-800 \mathrm{~N}$ corresponding to the individual weight $[6,7,9]$. Here, we consider the first harmonic (based on the design criteria), since it was readily discussed that the contribution of remaining harmonics is small.

A resonance response function is defined as [4]

$$
\frac{a}{g}=\frac{R F(t)}{\beta W}
$$

Hence, the maximum system acceleration can be expressed by substituting $F(t)$ from (4) as follows:

$$
\frac{a}{g}=\frac{R P \alpha_{i} \cos \left(2 \pi i f_{s} t\right)}{\beta W},
$$

where $a$ is the floor accelerations and $g=9.81 \mathrm{~m} / \mathrm{s}^{2}$ is the gravity acceleration. $W$ and $\beta$ are the floor effective weight and the modal damping ratio, respectively. In this model, the reduction factor, $R$, which is treated as the human activities, like walking and running, does not fully permit the steadystate resonant motion such that it is equivalent to 0.5 and 0.7 for floor structures and footbridges, respectively [4]. According to the design criteria, the lowest harmonic where the excitation frequency coincides the structural natural frequency has to be chosen to calculate peak acceleration due to human running in (6).
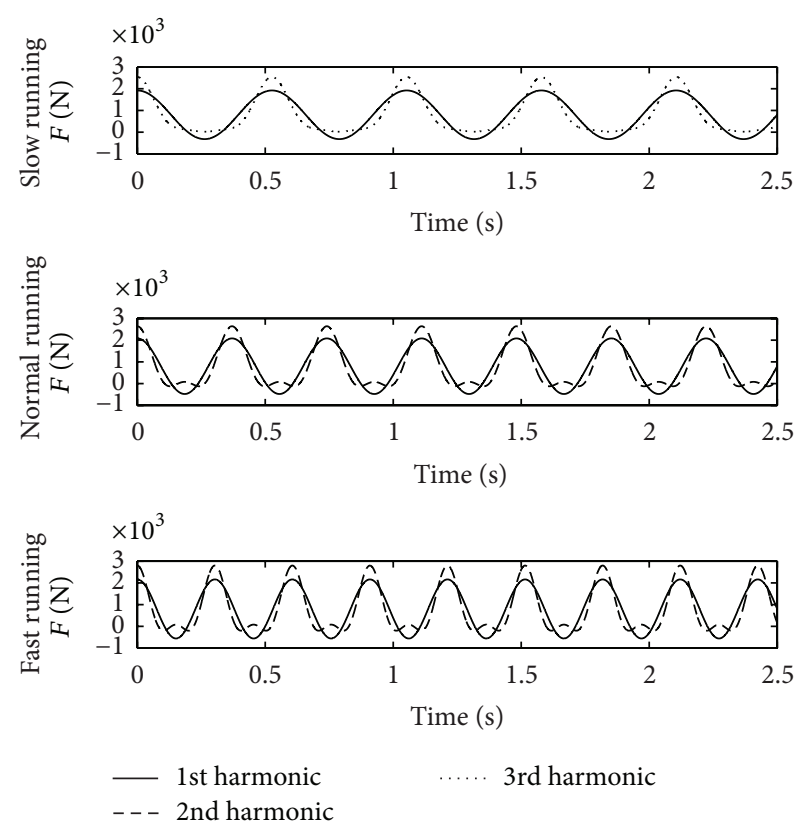

FIGURE 3: The dynamic load functions when a person is jogging, performing standard running or sprinting.

\section{Load Modeling}

The load model developed in this investigation uses dynamical effects of different types of running induced loads by people. When a person is running, the weight of human body is substantial in each step due to its acceleration and frequency which makes the floor system react. In any case of this investigation, a three-component force is being applied to the footbridges due to the ground reaction induced by the acceleration of the pedestrian motion. Only the vertical component load is taken into account in this study. The lateral and longitudinal loads are neglected because the longitudinal load is not important in vibration analyses, and the magnitude of the lateral load is just $4 \%$ of the vertical component [10].

In the case of sprinting and standard running, the loads applied to the footbridges are a two-component harmonic load and the human body weight. Nevertheless, in the case of the jogging, a three-component harmonic load and also the human body weight are considered as applied loads. The loads are assigned at the middle of the span due to one-foot loading. To model running load, the synchronous participation of the static and dynamic loads is considered. The static load is due to human body weight, and dynamic load is corresponding to the Fourier series based on timedomain repeated forces (3).

Dynamic loads such as slow, normal, and fast running are applied the whole time of pedestrian crossing the footbridge to illustrate the human running load as a function of time. It is shortened to 2.5 seconds in this paper. Figure 3 shows the dynamic load functions when a person is running slowly, normally, or fast. Corresponding step frequency for jogging (slow running), normal running, and sprinting (fast running) 


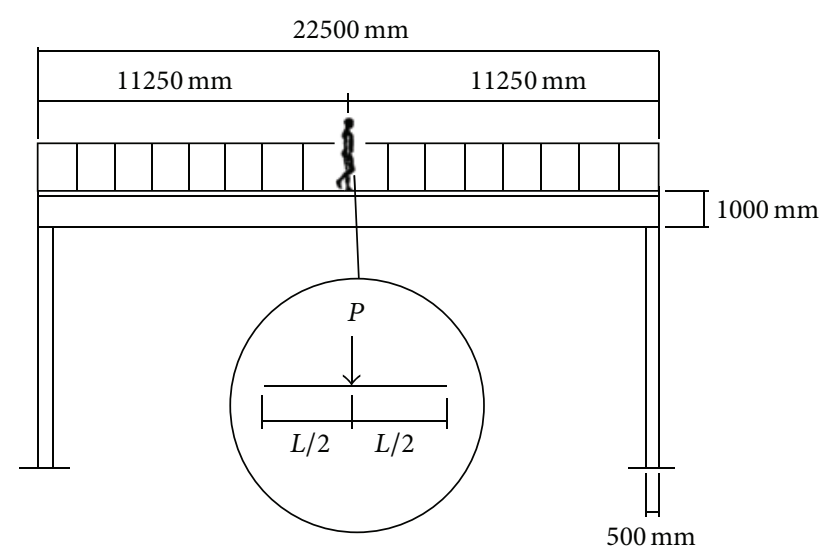

FIgURE 4: The applied load model on the footbridge [6].

is $1.9 \mathrm{~Hz}, 2.7 \mathrm{~Hz}$, and $3.3 \mathrm{~Hz}$, respectively, in the first harmonic and the harmonic in which resonance occurs.

\section{Structural Model}

We consider a bridge structure that was investigated in the existing literature. The structural model studied by da Silva et al. [5] is a composite pedestrian footbridge supported at two ends of span by columns with a reinforcement concrete slab and a I shape steel beam section as shown in Figures 4 and 5 . The constructed model is characterized by $22.5 \mathrm{~m}$ and $2.30 \mathrm{~m}$, respectively, for the length and the width of the span.

The structural system comprises a concrete slab with a thickness of $100 \mathrm{~mm}$ and composite girders. The geometrical characteristics of the cross section of the footbridge are shown in Figure 5 and Table 1.

The mechanical characteristics of the steel sections utilized as girders are welded wide flange with Young's modulus of $2.05 \times 10^{5} \mathrm{MPa}$ and a yield stress steel grade of $300 \mathrm{MPa}$. In addition, Young's modulus for concrete slab is $3.84 \times 10^{4} \mathrm{MPa}$, and its compression strength is $30 \mathrm{MPa}$. A damping ratio of $\beta=3 \%$ is taken into account [6].

\section{Computational Model}

The designated finite element model uses three-dimensional solid elements for both the composite slab and steel girder developed in the SAP2000 [11]. The developed computational finite element model with 27228 degrees of freedom includes 2340 solid elements and 4550 nodes. Verification of the numerical simulation is based on a comparison of its fundamental frequency to that from the technical literature. We find a similar first natural frequency to that of da Silva et al. [5] for this structure as shown in Table 2.

As a result, the model with aforementioned setting was considered as the computational model of the investigated structure and used from herein in further exploration.
TABLE 1: The geometrical characteristics of steel sections [5].

\begin{tabular}{lcc}
\hline Beams & VS $900 \times 159$ & I $200 \times 27.3$ \\
\hline Height $(\mathrm{mm})$ & 900 & 203.2 \\
Flange width $(\mathrm{mm})$ & 350 & 101.6 \\
Top flange thickness $(\mathrm{mm})$ & 19 & 10 \\
Bottom flange thickness $(\mathrm{mm})$ & 19 & 10 \\
Web thickness $(\mathrm{mm})$ & 8 & 6.86 \\
\hline
\end{tabular}

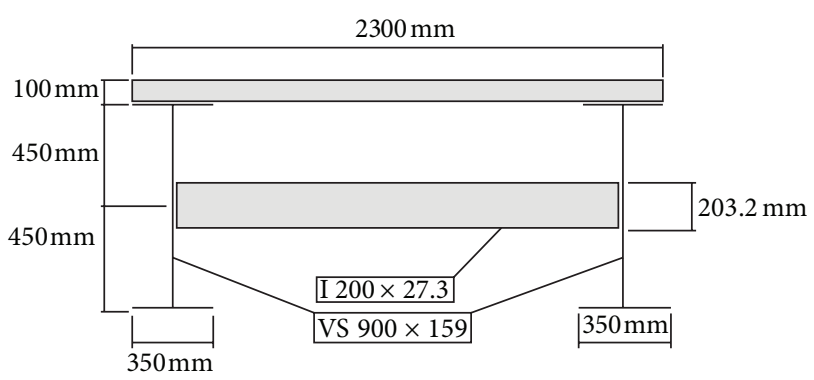

FIGURE 5: The geometrical characteristics of the cross section of footbridge [6].

\section{Dynamical Analysis of Structure}

The vibration response of the structure was estimated in terms of natural frequencies, accelerations, and displacements through a linear time-history modal analysis. As a result, to the assessment of a probable excessive vibrations which generate the human unsafe condition, the maximum acceleration and displacement are compared to the current design standards $[4,11,12]$.

7.1. Natural Frequency. As mentioned before, in this investigation the first natural frequency acquired from the finite element model is $5.4 \mathrm{~Hz}$. Figure 6 represents the mode shapes of the first to sixth natural frequencies of our model, all of which demonstrate ascent and descent movements of the footbridge when it vibrates.

7.2. Acceleration and Displacement. The limiting peak accelerations $[13,14]$ as well as displacements $[4,11,13]$ are provided by the design criteria. Generally, the limiting acceleration values are remarked as the percentage of the acceleration of gravity. These values are recommended by ISO 2631-2 [12], Ontario Bridge Code [15], and BS 5400 (British Standard) $[16,17]$ as shown in Table 3 . From the conducted numerical model analyses, the maximum accelerations resulted from excitation loads of one person running as slow, normal, and fast are $0.14 \% \mathrm{~g}, 0.15 \% \mathrm{~g}$, and $0.16 \% \mathrm{~g}$, respectively.

As illustrated in Figure 7, the vertical accelerations at the midspan of the structure are time-dependent function with an absolute maximum value comparable with the vibration serviceability criteria.

Despite the fact that the vertical acceleration increases and decreases with some periodic fluctuations, its value decreases with time step size of 0.01 second, which then reduces 


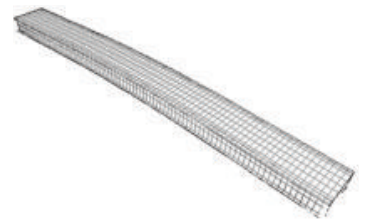

(a)

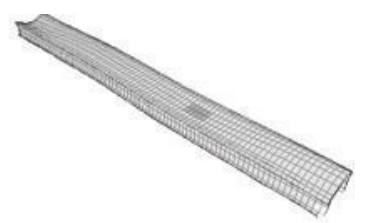

(d)

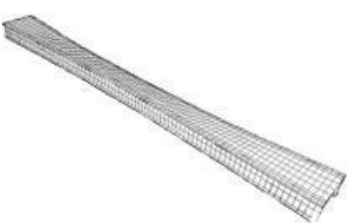

(b)

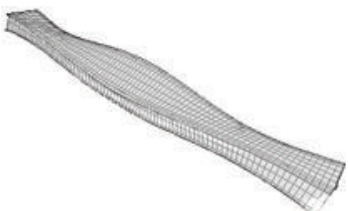

(e)

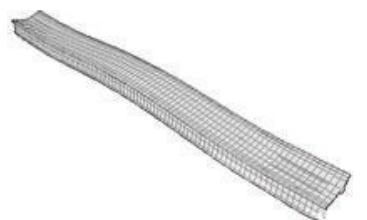

(c)

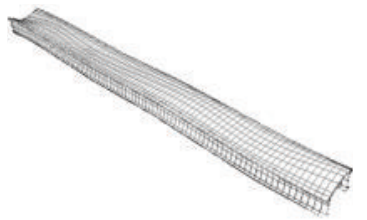

(f)

Figure 6: The mode shapes of the (a) first, (b) second, (c) third, (d) fourth, (e) fifth, and (f) sixth natural frequencies.

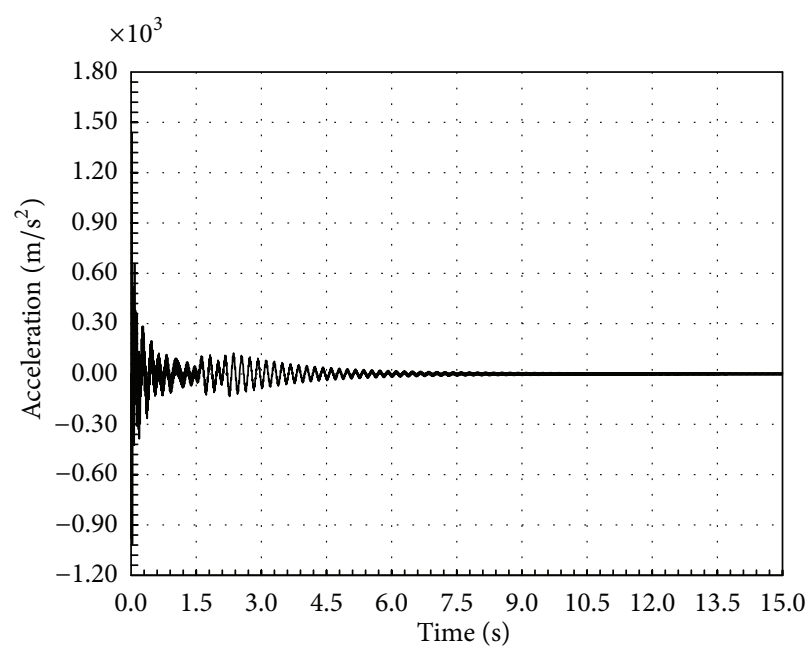

(a)

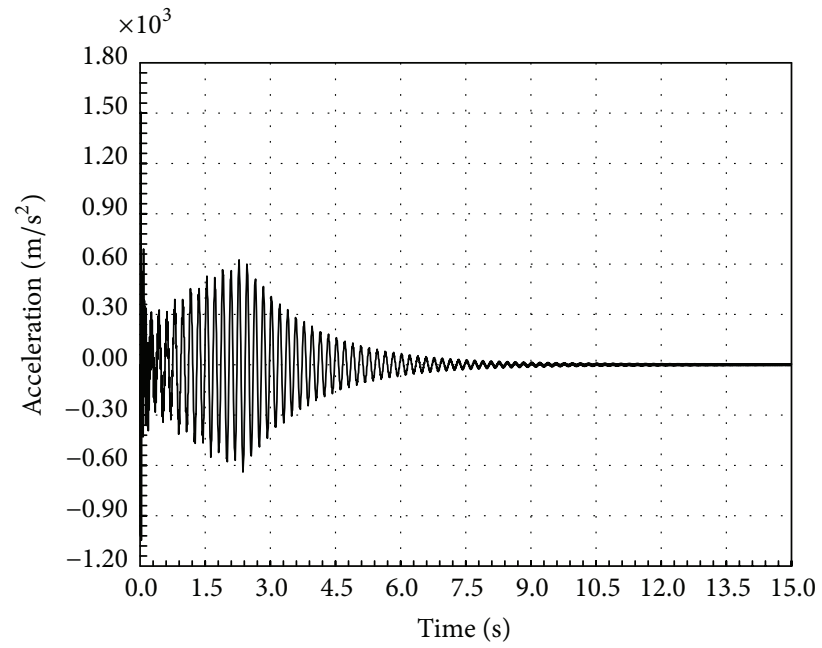

(b)

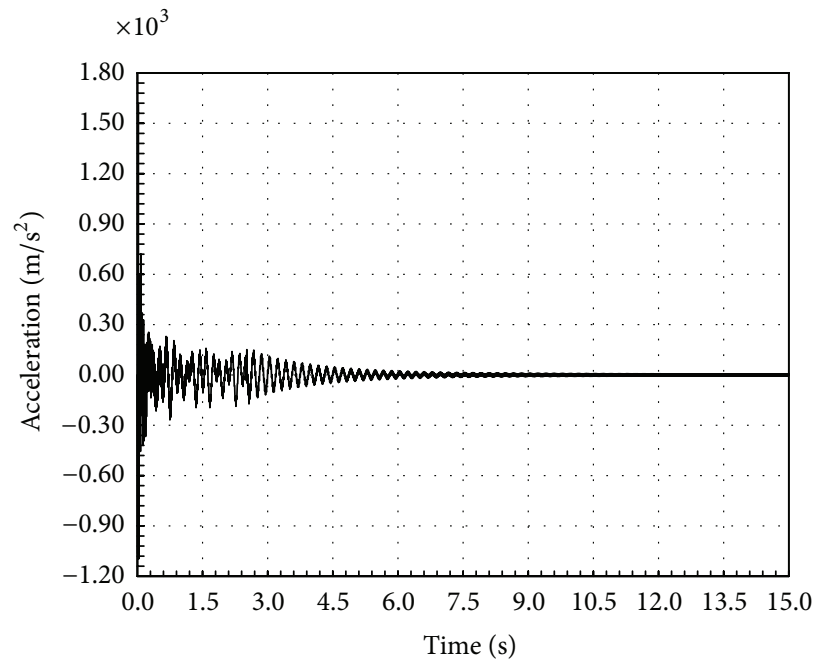

(c)

FIGURE 7: The vertical accelerations at the midspan of the structure due to (a) jogging, (b) normal running, and (c) sprinting. 
TABLE 2: Modeled natural frequencies compared with da Silva et al. [5].

\begin{tabular}{lccccc}
\hline$f_{i}$ & $f_{1}$ & $f_{2}$ & $f_{3}$ & $f_{4}$ & $f_{5}$ \\
\hline Natural frequencies (Hz) calculated in this paper & 5.4 & 13.64 & 22.51 & 28.41 & 30.18 \\
Natural frequency from [5] & 5.5 & - & - & - & - \\
\hline
\end{tabular}

TABLE 3: The peak accelerations for outdoor footbridge (a) jogging, (b) normal running, and (c) sprinting.

\begin{tabular}{lccr}
\hline Max acceleration $a_{\max }(\% \mathrm{~g})$ & \multicolumn{2}{c}{ Limitation of peak acceleration } \\
\hline (a) $0.14 \% \mathrm{~g}$ & ISO 2631-2 [9] & ONT [15] & BS 5400 [16, 17] \\
(b) $0.15 \% \mathrm{~g}$ & $5 \% \mathrm{~g}$ & $3.46 \% \mathrm{~g}$ & $11.95 \% \mathrm{~g}$ \\
(c) $0.16 \% \mathrm{~g}$ & & & \\
\hline
\end{tabular}

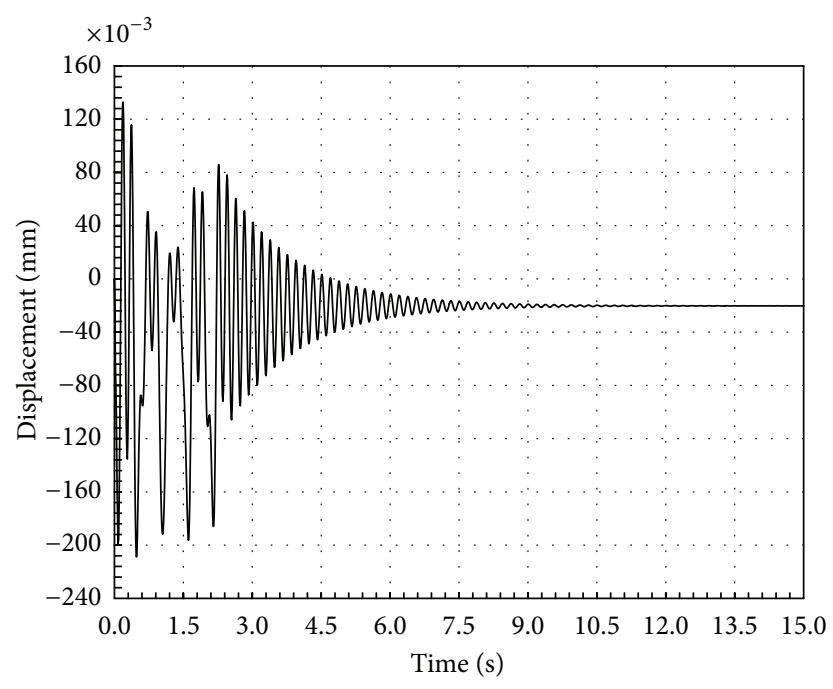

(a)

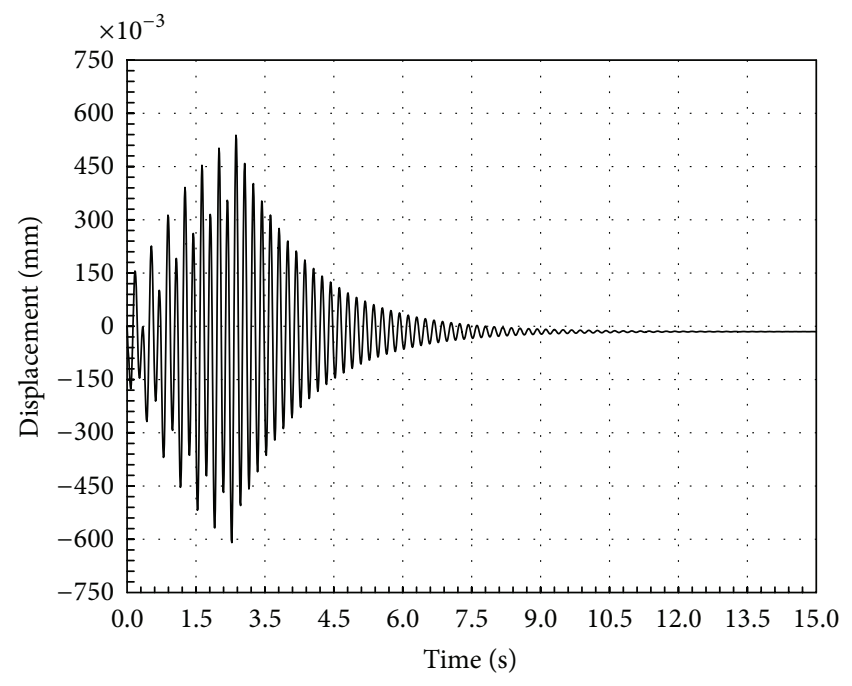

(b)

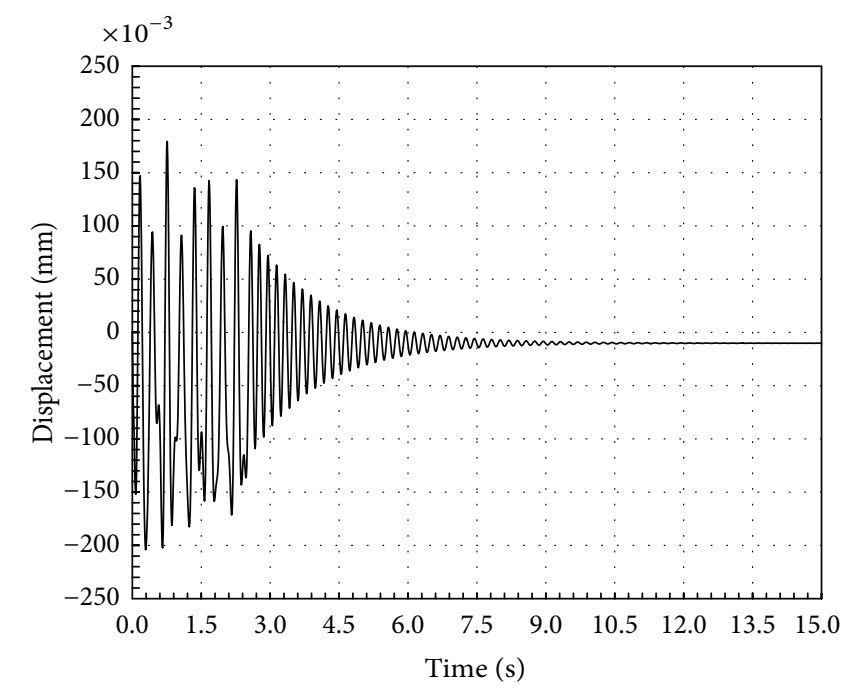

(c)

FIGURE 8: The vertical displacements at the midspan of the structure due to (a) jogging, (b) normal running, and (c) sprinting. 
to zero after 1500 time steps. These fluctuations are due to coincidence of the frequencies of dynamic force and natural frequency in different times which delineate maximum acceleration as a result of resonance at that particular time and value of force. It is clearly observable that the footbridge structure maximum accelerations as results of dynamic load motivation of jogging, normal running, and sprinting can satisfy all limitations as shown in Table 3. Therefore, there is an absence of any human unsafety and uncomfort when one person runs with different frequencies on the footbridge, even though the values of the acceleration are intensified from $0.14 \% \mathrm{~g}$ to $0.16 \% \mathrm{~g}$ with increasing step frequency.

On the other hand, the bridge design specifications of AASHTO LRFD recommend the design criteria for displacement of the pedestrian crossing structure like outdoor footbridges [13]. According to these criteria, footbridge structure maximum allowable deflection in the midspan should not exceed $L / 1000$ ( $L$ is the length of the span). The maximum displacements at midspan obtained from the model analyses are $0.21 \mathrm{~mm}, 0.6 \mathrm{~mm}$, and $0.2 \mathrm{~mm}$ for slow, normal, and fast running, respectively. As elucidated in Figure 8(b), the vertical displacements at the midspan are time-dependent with a maximum value of $0.6 \mathrm{~mm}$ for normal running which obeys the serviceability design criteria. In addition, Figures 8(a) and 8 (c) represent the time-dependent displacement values at the midspan for jogging and fast running, with a maximum value of $0.21 \mathrm{~mm}$ and $0.2 \mathrm{~mm}$, respectively, which also comply with the serviceability criteria. Based on the design criteria and considering $22.5 \mathrm{~m}$ for the length of the span, the limiting displacement value for this footbridge is equal to $22.5 \mathrm{~mm}$. Therefore, the maximum displacements are not critical for all the considered cases; that is, the outdoor footbridge structure that is analyzed in this paper can satisfy limiting values for displacements.

\section{Conclusion}

Composite footbridges have been increasingly constructed by structural designers to obtain an unprecedented slenderness using new materials and technologies. In this paper, assessment of serviceability limit state is carried out through a dynamic analysis of a slender footbridge when subjected to various human running loads. A structural bridge from the literature is modeled to obtain the accurate amount of natural frequency that conforms to previous investigation. A reasonably accurate mathematical load model has been used to describe the action of these loads on the footbridge. Moreover, the footbridge structure maximum accelerations and displacements were also examined and compared with existing design criteria from available standards. From the conducted finite element model, the first natural frequency was $5.4 \mathrm{~Hz}$ which agrees with reported value from assisting study. In addition, the maximum accelerations and displacements of the footbridge structure were safely satisfied from all practical guide limitations, for three different types of human running (jogging, normal running, and sprinting).

\section{Conflict of Interests}

The authors declare that there is no conflict of interests regarding the publication of this paper.

\section{References}

[1] A. Occhiuzzi, M. Spizzuoco, and F. Ricciardelli, "Loading models and response control of footbridges excited by running pedestrians," Structural Control and Health Monitoring, vol. 15, no. 3, pp. 349-368, 2008.

[2] V. Racic, A. Pavic, and J. M. W. Brownjohn, "Experimental identification and analytical modelling of human walking forces: literature review," Journal of Sound and Vibration, vol. 326, no. 1-2, pp. 1-49, 2009.

[3] S. P. Carroll, J. S. Owen, and M. F. M. Hussein, "Modelling crowd-bridge dynamic interaction with a discretely defined crowd," Journal of Sound and Vibration, vol. 331, no. 11, pp. 26852709, 2012.

[4] T. M. Murray, A. David, and E. E. Ungar, Steel Design Guide 11: Floor Vibrations due to Human Activity, American Institute of Steel Construction, 2003.

[5] J. G. S. da Silva, P. C. G. D. S. Vellasco, S. A. L. de Andrade, L. R. O. de Lima, and F. P. Figueiredo, "Vibration analysis of footbridges due to vertical human loads," Computers and Structures, vol. 85, no. 21-22, pp. 1693-1703, 2007.

[6] C. C. Caprani, J. Keogh, P. Archbold, and P. Fanning, "Enhancement factors for the vertical response of footbridges subjected to stochastic crowd loading," Computers and Structures, vol. 102103, pp. 87-96, 2012.

[7] S. Živanović, A. Pavic, and P. Reynolds, "Vibration serviceability of footbridges under human-induced excitation: a literature review," Journal of Sound and Vibration, vol. 279, no. 1-2, pp. 174, 2005.

[8] M. Pańtak, "Elaboration of the vibration comfort criteria for footbridges during vibrations induced by pedestrians," in Proceedings of the 6th International Conference on Bridge Maintenance, Safety and Management (IABMAS '12), pp. 2334-2339, Stresa, Italy, 2012.

[9] ISO, "Evaluation of human exposure to whole-body vibration," in Part 2: Continuous and Shock-Induced Vibration in Buildings (1-80 Hz), ISO 2631-2, 1989.

[10] D. P. Thambiratnam, N. Perera, C. Abeysinghe, M. H. Huang, and S. de Silva, "Human activity-induced vibration in slender structural systems," Structural Engineering International, vol. 22, no. 2, pp. 238-245, 2012.

[11] "SAPU Manual, Computers and Structures," Berkeley, Calif, USA, 2005.

[12] H. Bachmann and W. Ammann, "Vibrations in structures induced by man and machines," IABSE Structural Engineering Document 3E, International Association for Bridges and Structural Engineering.

[13] AASHTO LRFD Bridge Design Specifications: Customary U.S. Units, American Association of State Highway and Transportation Officials, 2005.

[14] F. N. Leitão, J. G. S. da Silva, P. C. G. S. da Vellasco, S. A. L. de Andrade, and L. R. O. de Lima, "Composite (steel-concrete) highway bridge fatigue assessment," Journal of Constructional Steel Research, vol. 67, no. 1, pp. 14-24, 2011.

[15] Ontario Highway Bridge Design Code, Ontario Ministry of Transportation, Quality and Standards Division, 1991. 
[16] J. G. S. da Silva, P. C. G. D. S. Vellasco, S. A. L. de Andrade, F. J. D. C. P. Soeiro, and R. N. Werneck, "An evaluation of the dynamical performance of composite slabs," Computers and Structures, vol. 81, no. 18-19, pp. 1905-1913, 2003.

[17] H. M. Faridani and M. Barghian, "Improvement of dynamic performances of suspension footbridges by modifying the hanger systems," Engineering Structures, vol. 34, pp. 52-68, 2012. 

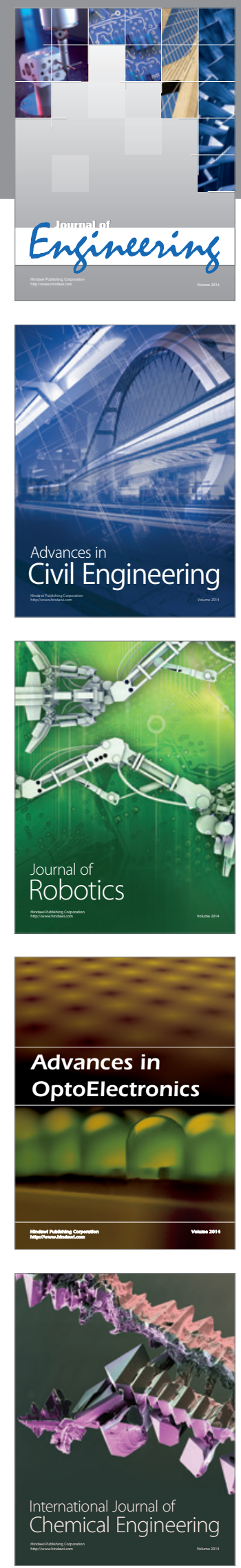

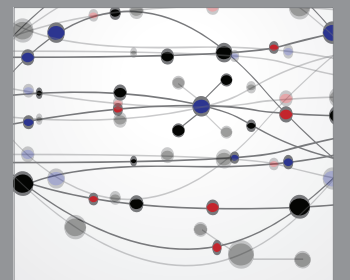

The Scientific World Journal
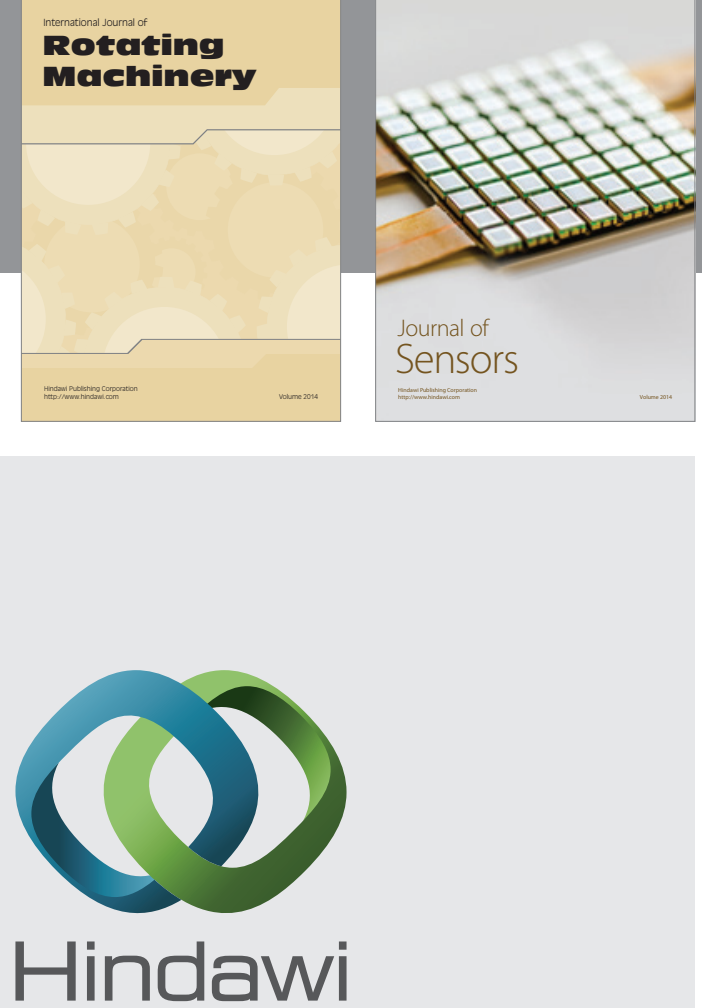

Submit your manuscripts at http://www.hindawi.com
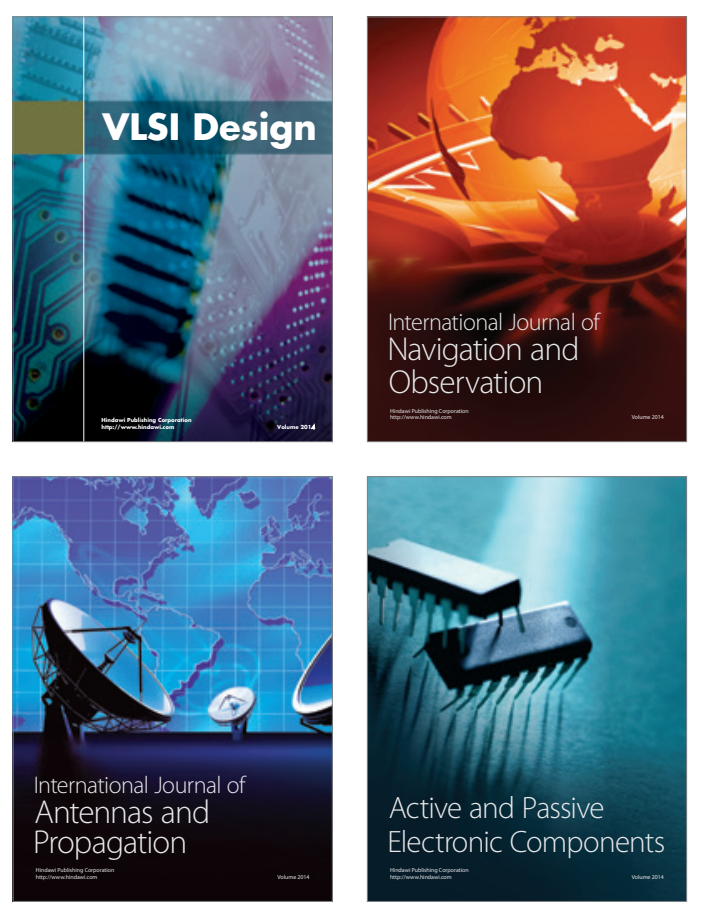
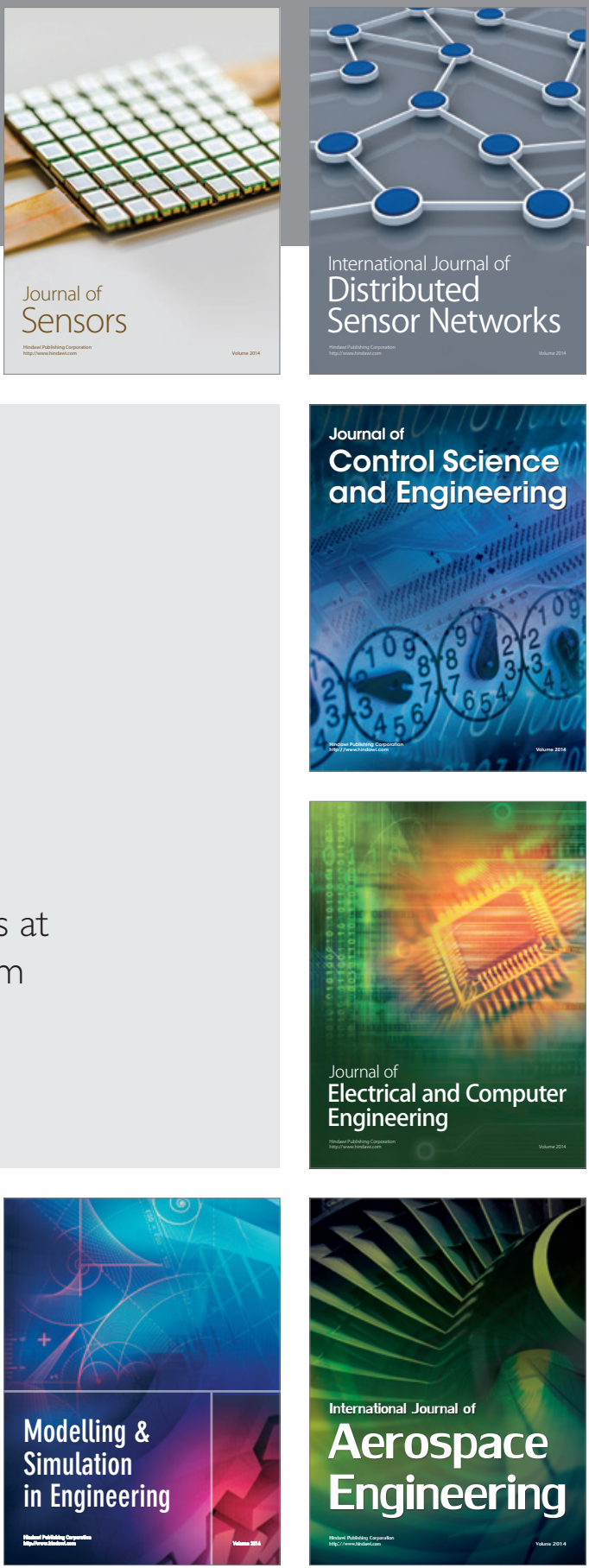

Journal of

Control Science

and Engineering
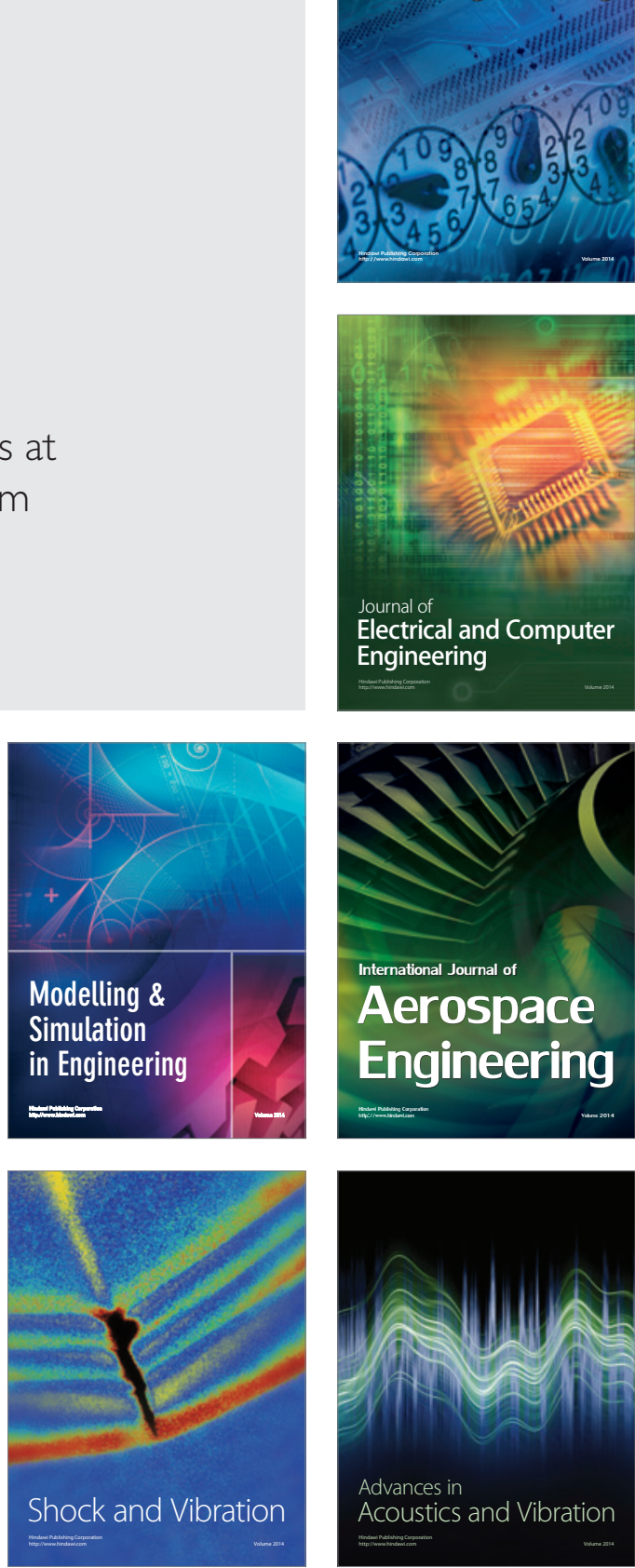